\title{
Recent advances and novel concepts in environmental technologies
}

\author{
Eldon Raj Rene ${ }^{1} \cdot$ Li Shu $^{2} \cdot$ Veeriah Jegatheesan ${ }^{3}$ \\ Published online: 10 April 2020 \\ (C) Springer-Verlag GmbH Germany, part of Springer Nature 2020
}

This special issue contains 17 articles that are disseminating the recent advances and novel concepts in environmental technologies. They are selected from the presentations made at the 11th annual international conference on the "Challenges in Environmental Science and Engineering," CESE-2018 that was held in Bangkok, Thailand from the 4th to the 8th of November 2018. There were 274 delegates from 18 countries and regions participated in CESE-2018. The conference covered 8 themes, namely, (i) the application of Membrane Technology \& Nano-Technology, (ii) Water \& Wastewater: Pollution Prevention \& Treatment, (iii) Resources \& Wastes: Management and Recovery of Materials and Energy, (iv) Air Pollution: Prevention and Treatment, (v) Sustainable Catchments \& Renewable Energy, (vi) Cleaner Production and Emerging Sustainable Practices, (vii) Appropriate Technology for Sustainability \& Climate Change Adaptation/Mitigation, and (viii) Soil Sustainability and Contaminated Soils and Sediments. This special issue covers various aspects of adsorption, heavy metals, application of membranes, removal of pollutants, water quality, and treatment as well as climate change and education.

Three articles are dedicated to adsorption. One article discusses the adsorption of copper from aqueous media using chitosan-coated bentonite, chitosan-coated sand, and

Responsible editor: Philippe Garrigues

Veeriah Jegatheesan

jega.jegatheesan@rmit.edu.au

1 UNESCO-IHE Institute for Water Education, Westvest 7, 2611, AX Delft, The Netherlands

2 LJS Environment, 2 Parkville Avenue, Parkville, VIC 3052, Australia

3 School of Engineering, RMIT University, Melbourne, VIC 3052, Australia chitosan-coated kaolinite using fixed-bed. All the media showed the removal of $\mathrm{Cu}$ (II) between 56 and $68 \%$ at $\mathrm{pH} 3.0$ for an initial $\mathrm{Cu}$ (II) concentration of $200 \mathrm{mg} / \mathrm{L}$. Regeneration studies were conducted using $0.1 \mathrm{M} \mathrm{HCl}$ and $0.1 \mathrm{M} \mathrm{NaOH}$. The second article evaluates the combinatorial optimality of functional groups, process parameters, and $\mathrm{Pd}$ (II) adsorption-desorption characteristics for commercial anion exchange resins-synthetic electroless plating systems. The study found that contrary to the generalized rule of thumb that considers sulfur-nitrogen functional group containing commercial resins to be effective in adsorbing Pd (II), resins with nitrogen-oxygen functional groups were more effective. Further, since due to functional group interactions with the noble metal, no other by-products or exchanged chemicals have been produced during the adsorption process. The third article studies the adsorptive removal of cationic tricyclic antidepressants using cation-exchange resin. It was found that combination of electrostatic and $\pi-\pi$ interactions between the positively ionized tricyclic antidepressants (TCAs) and the cation exchange resin Dowex 50WX4-200 may have led to high uptakes of the TCAs.

Three more articles deal with various aspects of heavy metals. The first article in this section carries out life cycle assessment of heavy metal contaminated sites that undergo phytoremediation and soil excavation. The second article reports the outcomes of batch and continuous studies on the removal of heavy metals from aqueous solution using biosynthesized melanin-coated polyvinylidene fluoride (PVDF) membranes. Melanin nanoparticles were derived from the marine bacterium Pseudomonas stutzeri and were coated onto hydrophobic polyvinylidene fluoride (PVDF) membrane as a support. Heavy metals such as $\mathrm{Hg}$ (II), $\mathrm{Cr}$ (VI), $\mathrm{Pb}$ (II), and $\mathrm{Cu}$ (II) were all had more than $87 \%$ removal at $45^{\circ} \mathrm{C}$ and a $\mathrm{pH}$ of 3 for chromium and 5 for other metals. The third article evaluates the influence of Pseudomonas japonica and organic amendments on the growth and metal 
tolerance of Celosia argentea L., a herbaceous plant of tropical origin. It was found that the production of antioxidant enzymes such as catalase (CAT), ascorbate peroxidase (APX), guaiacol peroxidase (GPX), and glutathione-stransferase (GST) were high in $P$. japonica-amended plants because of increased uptake of metals.

The next two articles are dedicated to the enhancement of photocatalysis. The first article studies doping $\mathrm{TiO}_{2}$ with $\mathrm{CuSO}_{4}$ to enhance the photocatalytic activity of visible light for degrading organic pollutants. A doping level of $0.21 \%$ (mol) $\mathrm{CuSO}_{4}$ was identified as optimum condition to enable visible light photocatalysis of doped $\mathrm{TiO}_{2}$ catalysts calcined at $300{ }^{\circ} \mathrm{C}$. Under a wide range of $\mathrm{pH}, 3.0 \mathrm{~g} \mathrm{~L}^{-1}$ of catalyst was dosed to treat up to $20 \mathrm{~g} \mathrm{~L}^{-1}$ of highly recalcitrant phenothiazine dye and complete removal of dye under visible light was obtained after $120 \mathrm{~min}$ of treatment. The next article is on a comparative study of two kinds of $\beta-\mathrm{Bi}_{2} \mathrm{O}_{3} / \mathrm{TiO}_{2}$ binary composite and their removal of $17 \alpha$-ethynyl estradiol. $\mathrm{TiO}_{2}$ nanobelts and P25 particles were used as titanium sources, and the enhanced photocatalytic activities of two kinds of composites are ascribed to photo-induced interfacial charge transfer on the heterojunction between $\beta-\mathrm{Bi}_{2} \mathrm{O}_{3}$ and $\mathrm{TiO}_{2}$ or P25.

The next two articles deal with the removal and formation of disinfection by-products (DBPs). Thus, one article studies the factors affecting the removal of bromate and bromide in water by nanofiltration and the other article analyzes the models for predicting carbonaceous disinfection by-product formation in drinking water treatment plants using a case study in South Korea. In the first study, it was found that the removal of those anions $\left(\mathrm{Br}-\right.$ and $\left.\mathrm{BrO}_{3}{ }^{-}\right)$was enhanced by increasing the $\mathrm{pH}$ as well as decreasing ionic strength of the solution. Compared with humic acid, severer flux decline and deterioration of anion removal were observed when sodium alginate was added in feed solution as an organic substance. Regardless of the operating conditions, bromate was removed easily by nanofiltration membranes than bromide, which could be due to different steric hindrance. In the second paper, variables such as dissolved organic carbon, ultraviolet absorbance, residual chlorine, bromide, contact time, chlorine dose and temperature of treated water, and $\mathrm{pH}$ for both raw and treated water at the plant are considered in developing linear models for both trihalomethanes (THMs) and haloacetic acids (HAAs).

Development of a molasses wastewater treatment system equipped with a biological desulfurization process and optimization of reactive media for removing organic micropollutants in constructed wetland treating municipal landfill leachate are discussed in the next two articles. In the first article, it was shown that the combination of an anaerobic baffled reactor (ABR) and a two-stage down-flow hanging sponge (TSDHS) reactor (ABR-TSDHS system) can be applied to not only molasses wastewater treatment but also the desulfurization of the produced biogas in the ABR. the first down-flow hanging sponge (DHS) reactor achieved $87.3 \%$ hydrogen sulfide removal via dissolution into sprinkled effluent water. This dissolved sulfide was oxidized to sulfate in the second DHS in the absence of aeration. In the second study, the use of sand, clay, and iron powder media at $60: 30: 10 \%(\mathrm{w} / \mathrm{w})$ ratio and cattail as vegetation was found optimum for the removals of organic micropollutants such as 2,6-di-tert-butylphenol (2,6-DTBP), 2,6-di-tert-butyl-4methylphenol (BHT), diethyl phthalate (DEP), di-butyl phthalate (DBP), and bis(2-ethylhexyl) phthalate (DEHP) at $67.5-75.4 \%$ during a long-term study (373 days of operation).

The next article explores the effects of carbendazim (widely used fungicide as well a casting worm control agent in golf greens, tennis courts, etc.) on catalase activity and related mechanism. Catalase is a very important enzyme in protecting the cell from oxidative damage by reactive oxygen species (ROS). The next article conducts a proximate analysis and fatty acid of Corbicula fluminea (C. fluminea, a clam) tissue. It is important to find how the handling process of C. fluminea at different processing stages (raw, smoke, and selling stages) affects the nutritional value.

Next two articles use two mathematical models to understand the science behind two very different situations. The first article works on the human continuous hydrogen cyanide inhalation predictor with a physiologically based pharmacokinetic (PBPK) model. The second article forecasts artificial neural network (ANN) model for predicting behavior of diesel engine energized by combination of two low viscous biofuel. The last article again deals with another different aspect related to environmental education of climate change. It evaluates the risk perception and response toward climate change for higher education students in Taiwan. Thus, this special issue brings valuable solutions to some interesting challenges in environmental science and engineering and adds new knowledge to the existing literature in their relevant areas.

The guest editors of this special issue are thankful to the editor in chief of Environmental Science and Pollution Control Journal, Professor Garrigues and the publishing editor Alexandrine Cheronet for providing an opportunity to publish selected peer-reviewed papers that were presented at CESE-2018. Thanks are also due to Ms. Fanny Creusot, editorial assistant, and the entire production team of the journal for their valuable support in bringing out this issue successfully. Last but not least, our sincere appreciation to all the reviewers for their invaluable and critical review comments on manuscripts that were submitted to this special issue. 


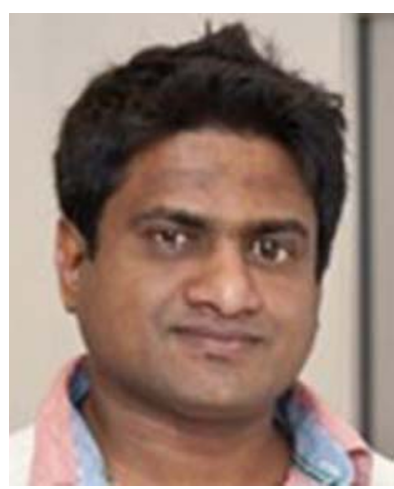

Eldon Raj Rene is a senior lecturer of Resource Recovery Technology at UNESCO-IHE, Institute for Water Education (Delft, The Netherlands). His research majorly focuses on the development of biological treatment processes for wastewater and waste gas treatment, non-point source pollution prevention, resource recovery from waste gases, the use of artificial intelligence tools for environmental monitoring, environmental process control, and eco-industrial parks. He has authored two books on Sustainable Heavy Metal Remediation (Vols. 1 and 2, published in 2017 by Springer), and he currently serves as the managing editor for Reviews in Environmental Science and Bio/ technology (Springer) and as an associate editor of the Journal of Environmental Engineering (ASCE-JEE). He is also the two-time recipient of the Young Scientist Award conferred by the Challenges in Environmental Science and Engineering conference organizers in Sydney (Australia) and Kaohsiung (Taiwan), respectively. In 2007, he was awarded the Juan de la Cierva fellowship by the Ministry of Science and Innovation (Spain). Eldon has also edited special (thematic) issues and volumes in the following journals: Bioresource Technology, International Biodeterioration \& Biodegradation, Journal of Environmental Management, ASCE-Journal of Environmental Engineering, Journal of Hazardous Materials, and Environmental Science and Pollution Research. He is a life member at the International Bioprocessing Association (IBA). He is the co-chair of the following international conference series: Challenges in Environmental Science and Technology (CESE), Research Frontiers in Chalcogen Cycle Science \& Technology (G16), and Alternative Fuels, Energy and Environment (ICAFEE). As a part of his capacity building initiative, Eldon regularly conducts scientific writing and skill development workshops at major international conferences/meetings, as well as for students from developing countries.

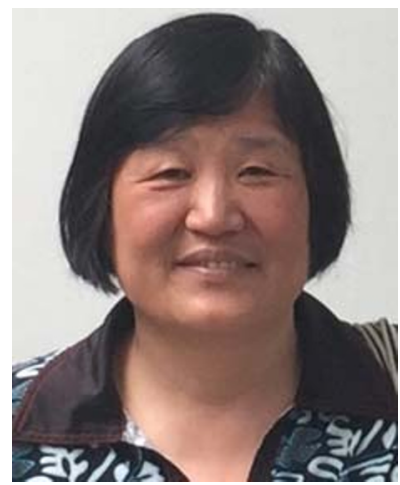

Li Shu is the Managing Director of LJS Environment, Australia and a Guest Professor at Shandong Normal University. She was a Senior Researcher at RMIT University, Australia until December 2016. Shu has more than 150 publications in the form of Books, Book Chapters, Journal Papers, and Refereed Conference papers. She obtained her Bachelor degree from Qingdao University of Science and Technology, China; Master degree from Asian Institute of Technology, Bangkok; and colleagues is the first to document images of water clusters taken by a microscope. They also proposed the structure of water, which has been published recently in Fluid Phase Equilibria. With the proposed structure of water, mysterious behaviors of water could be explained. The research group reported that $\mathrm{pH}$ of neutral salt was not 7 and the neutral salt was corrosive. Dr. Li Shu proposed that strong electrolyte such as $\mathrm{NaCl}$ existed in water as aggregates in 2005. The concept has been supported using a Nanosizer (Malvern) and results were published in 2013 and 2017. Li Shu's research interest is in water and wastewater treatment using membrane filters, resource recovery, and zero liquid discharge. Various membranes and nanoparticles have been employed for water and wastewater reclamation. She taught Water and Wastewater Systems to undergraduate and postgraduate students. She is one of the founders of an International Conference "Challenges in Environmental Science and Technology", CESE, and has been the co-chair of the Conference since 2008. She is an Editorial Board Member of Austin Environmental Sciences and SM Journal of Environmental Chemical Engineering. She is a guest editor of the following journals: Bioresource Technology; Desalination and Water Treatment; International Biodeterioration and Biodegradation; Water, Air and Soil Pollution: Focus; Reviews in Environmental Science and Bio/ Technology; and Membrane Water Treatment.

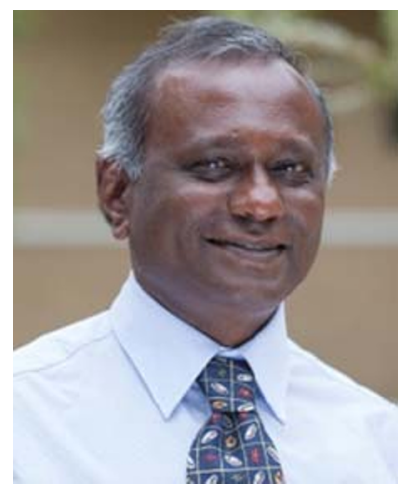

Veeriah Jegatheesan (Jega) is a Professor of Environmental Engineering and the Director of Water: Effective Technologies and Tools (WETT) Research Centre at RMIT University, Melbourne, Australia. Jega is the founder and Chairman of the international conference series on Challenges in Environmental Science \& Engineering (CESE) held annually since 2008. Jega has conducted extensive research on the application of membrane bioreactors, sugar cane juice clarification, sea water desalination, and the treatment of mine tailing ponds. He has over 370 publications including more than 140 peer-reviewed journal articles and five edited books. Jega is also the managing guest editor of 40 special issues in peer-reviewed journals. Recently, Stormwater Industry Association (Australia) has appointed him as one of the Governance Panel members for the Australian Stormwater Quality Improvement Device Evaluation Protocol (SQIDEP). Jega is the editor in chief of a book series entitled Applied Environmental Science and Engineering (AESE) for a Sustainable Future published by Springer and has been instrumental for publishing 12 books since 2015. Jega has been appointed as the editor in chief of Environmental Quality Management journal (Wiley Publisher) from Jan. 2020.

PhD from University of New South Wales, Sydney. She with her students 